\title{
Avaliação das autuações da Vigilância Sanitária municipal em serviços de alimentação em uma capital no nordeste do Brasil
}

\section{Evaluation of punishments of the municipal Sanitary Surveillance in food services from a Brazilian Northeast capital}

\section{Renata Lacerda Pessoa iD \\ Roberval Edson Pinheiro de Lima iD \\ Priscilla Moura Rolim \\ Larissa Mont'Alverne Jucá Seabra}

Sônia Soares* iD
Universidade Federal do Rio Grande do Norte (UFRN), Natal, RN, Brasil

\section{* E-mail: soniafilos@yahoo.com}

Recebido: 11 ago 2020 Aprovado: 12 fev 2021

\section{RESUMO}

Introdução: O papel regulador da vigilância sanitária implica, dentre outras, ações fiscalizatórias mediante lavratura de Autos de Infração nem sempre publicizados. Objetivo: Identificar a publicidade das decisões de Processos Administrativos Sanitários instaurados pela Vigilância Sanitária Municipal em Serviços de Alimentação de uma capital do Nordeste brasileiro e avaliar as penalidades impostas. Método: Estudo transversal de abordagem qualitativa, que utilizou a técnica de análise documental. Os dados foram obtidos a partir de consulta on-line ao Diário Oficial do Município, no período de 2015 a 2018. Resultados: Foram encontrados 509 processos, sendo 16,7\% em 2015, 35,9\% em 2016, 34,6\% em 2017 e 12,8\% em 2018. "Advertência" foi a penalidade mais aplicada, isoladamente, seguida por "multa". Advertência e multa foram aplicadas cumulativamente com "inutilização de produtos", respectivamente em $11,0 \%$ e 4,9\% dos casos. "Interdição total" foi aplicada sempre cumulada, 7,7\% com advertência e 1,4\% com multa. Foram mais penalizados: "restaurantes e similares" (22,3\%), "supermercados e hipermercados" $(10,3 \%)$, "lanchonetes, casas de chá, sucos e similares" e "minimercados, mercearias e armazéns" (ambos com 6,9\%). O maior percentual foi de estabelecimentos que não puderam ser classificados (36,7\%). Conclusões: Há publicidade das decisões, mas não das infrações. A sistematização e a avaliação das decisões de processos administrativos são mecanismos de prestação de contas à sociedade e podem ser importantes ferramentas de gestão em Vigilância Sanitária. Para uma avaliação dos fatores de risco minimizados ou eliminados por essa ferramenta seria necessário conhecer o que motivou a lavratura dos Autos de Infração.

PALAVRAS-CHAVE: Boas Práticas de Manipulação; Vigilância Sanitária; Serviços de alimentação

\footnotetext{
ABSTRACT

Introduction: The regulatory role of health surveillance implies inspection actions by drawing up infraction notices, which are not always publicized. Objective: To identify the publicity of Administrative Proceedings decisions established from assessments in food services by the Municipal Sanitary Surveillance of a Northeast capital of Brazil and to evaluate the punishments imposed. Method: Qualitative cross-sectional study, which used the technique of document analysis; the data were obtained from online consultation with the Official Gazette of the Municipality, from 2014 to 2018. Results: Between 2015 and 2018, 509 cases were found: $16.7 \%$ in 2015, 35.9\% in 2016, 34.6\% in 2017 and $12.8 \%$ in 2018. "Warning" was the most applied penalty, in isolation, followed by "fine". Warning and fine were applied cumulatively with "product destruction", in $11.0 \%$ e $4.9 \%$ of cases, respectively. "Total interdiction" was applied cumulatively, $7.7 \%$ with a warning and $1.4 \%$ with a fine. The most penalized services were: "restaurants and similar" (22.3\%), "supermarkets and hypermarkets" (10.3\%), "snack bars, tea houses, juices and similar"
} 
and "mini-markets, grocery stores and warehouses" (both with 6.9\%). The highest percentage is of establishments that could not be classified (36.7\%). Conclusions: There is publicity for decisions, but not for infractions. Systematization and evaluation of decisions on health administrative processes is an accountability mechanism and it can be an important health surveillance management tool. For an assessment of the risk factors minimized or eliminated by this tool, it would be necessary to know what motivated the drafting of the infraction notices.

KEYWORDS: Good Handling Practices; Health Surveillance; Food services

\section{INTRODUÇÃOO}

O Sistema Nacional de Vigilância Sanitária (SNVS) foi definido pela Lei $n^{\circ}$ 9.782, de 26 de janeiro de 19991, que também criou a Agência Nacional de Vigilância Sanitária (Anvisa), vinculada ao Ministério da Saúde, sob regime jurídico diferenciado das autarquias especiais e caracterizada pela independência administrativa, estabilidade de seus dirigentes e autonomia financeira. Para promover a proteção e a saúde da população, compete à Anvisa coordenar esse Sistema, exercendo atividades de regulação, normatização, controle e fiscalização na área de vigilância sanitária'.

A vigilância sanitária constitui importante campo de atuação do Sistema Único de Saúde (SUS), firmado a partir da Constituição Federal, na qual a saúde está consignada como direito de todos e dever do Estado ${ }^{2}$. Assim sendo, cabe ao Estado implementar políticas públicas capazes de garantir à população brasileira acesso universal a ações e serviços públicos de saúde, além de se empenhar em reduzir riscos de doenças e agravos, de modo a promover a segurança sanitária da população ${ }^{3}$.

Com a definição de vigilância sanitária dada pela Lei n ${ }^{\circ} 8.080$, de 19 de setembro de $1990^{4}$, que regulamenta as ações e serviços públicos destinados a promover, proteger e recuperar a saúde, o objeto de suas práticas voltou-se para os riscos decorrentes dos modos de produção e consumo de produtos e serviços, em uma clara afinidade com o conceito de saúde estabelecido pela Constituição Federal e com as mudanças nos processos tecnológicos decorrentes do avanço da ciência. Neste sentido, para além de uma ação de saúde pública, com vistas à prevenção e controle de riscos, proteção e promoção da saúde, a vigilância sanitária é também um instrumento da organização econômica da sociedade, o que a torna um espaço de disputa de interesses e valores, especialmente no contexto do avanço científico e tecnológico ${ }^{5,6}$.

Destaca-se, atualmente, o número crescente de pessoas que realizam refeições fora do lar, favorecendo o aumento do número de estabelecimentos voltados à alimentação coletiva ${ }^{7}$. Dados da Associação Brasileira de Empresas de Refeições Coletivas (Aberc) do ano de 2019 demonstraram um mercado que fornece cerca de 15 milhões de refeições coletivas por dia e que gerou um faturamento de mais de 21 bilhões de reais, além de empregar cerca de 250 mil trabalhadores ${ }^{8}$. No caso dos Serviços de Alimentação, o papel da vigilância sanitária é essencial, para fiscalizar e orientar, dentre outras, medidas de prevenção e controle das Doenças Transmitidas por Alimentos (DTA), uma vez que, nos anos de 2009 a 2018, restaurantes, padarias e similares constituíram o segundo local de ocorrência de surtos, segundo dados do Ministério da Saúde?.
As ações da Vigilância Sanitária (Visa) na área de alimentos visando proteger a saúde são necessárias, e a fiscalização é uma forma de intervir nos fatores de risco encontrados numa inspeção. Para tanto, ela deve se basear em normas e regulamentos técnicos, tais como a Resolução da Diretoria Colegiada (RDC) $n^{\circ} 216$, de 15 de setembro de $2004^{10}$ da Anvisa, que dispõe sobre o Regulamento Técnico de Boas Práticas para Serviços de Alimentação, entre outras. O exercício do poder de polícia é inerente ao escopo da Visa e deve ser utilizado de modo equilibrado, sem jamais esquecer a sua finalidade, qual seja, a supremacia do interesse público. É importante considerar que o poder de polícia administrativa permite que a autoridade sanitária lance mão de medidas preventivas, materializadas nas autorizações, notificações, licenças, atos fiscalizatórios e medidas repressivas, tais como interdição de atividade, apreensão de mercadorias, inutilização de produtos e aplicação de multas ${ }^{3}$.

No tocante à área de alimentos, diversos estudos apontam o descumprimento da RDC $n^{\circ} 216 / 2004$, revelando falhas na segurança de alimentos, seja em escolas públicas ${ }^{11}$, restaurantes comerciais $^{12}$ ou restaurantes populares ${ }^{13}$.

São raros, porém, estudos que demonstrem quais instrumentos legais a Visa utilizou no exercício do poder de polícia na área de alimentos, quando constatado o descumprimento da norma ${ }^{14}$. Especificamente na área mais afim a este estudo, um mapeamento da produção científica em gestão da vigilância sanitária no Brasil, mostrou um crescimento significativo, mas incipiente, de publicações de artigos na área, além de um aumento da quantidade de dissertações e teses e quantidade limitada de revistas científicas que privilegiam o tema, com predomínio de publicações na região Sudeste ${ }^{15}$.

A realização de estudos e pesquisas que busquem responder às necessidades da sociedade é um dos instrumentos de que dispõe a vigilância sanitária para garantir sua ação regulatória ${ }^{16}$. É inerente à sua prática o exercício do poder de polícia, sendo talvez esta a sua face mais visível perante a sociedade ${ }^{17}$. Deste modo, o estudo das decisões de Processos Administrativos Sanitários (PAS), gerados pelo Auto de Infração, e o conhecimento das penalidades aplicadas face às infrações cometidas podem ser uma importante ferramenta de gestão para a tomada de decisões, especialmente no âmbito das estratégias de capacitação e treinamento da força de trabalho em Visa, com impactos na eficácia do controle sanitário ${ }^{18}$. 
Além disso, a Lei $\mathrm{n}^{\circ} 12.527$, de 18 de novembro de $2011^{19}$, conhecida como Lei de Acesso à Informação (LAl), que regulamenta o princípio da publicidade, reconhece o direito fundamental do cidadão de conhecer os atos da Administração, obrigando à ampla divulgação dos atos administrativos, dentre os quais, a imposição de penalidade após a decisão final do PAS.

Assim, o objetivo do estudo foi identificar, a partir de pesquisa documental em Diário Oficial do Município (DOM), a publicação das decisões de PAS instaurados em Serviços de Alimentação pela Visa Municipal de uma capital do Nordeste brasileiro e avaliar as penalidades impostas. Pretende-se com isso, preencher parte da grande lacuna existente na comunidade científica a respeito deste tema, além de estimular o desenvolvimento de futuros projetos de pesquisa nessa área. Entende-se que os resultados do estudo poderão ser úteis ao serviço, não apenas para avaliar suas práticas, mas também para auxiliar na construção de indicadores de avaliação em vigilância sanitária e contribuir no processo de planejamento nesse campo de atuação.

\section{MÉTODO}

A pesquisa caracterizou-se como um estudo transversal, de abordagem quantitativa, que utilizou a técnica de análise documental. A coleta de dados sobre as decisões de processos administrativos da Visa foi realizada em dois momentos, no mês de setembro de 2018 e janeiro de 2019. Mediante consulta on-line ao portal de acesso às informações da prefeitura, direcionou-se a busca pelas publicações do DOM, utilizando os seguintes critérios (Figura 1):

- Data da decisão publicada em DOM no período de $1^{\circ}$ de janeiro de 2014 a 31 de dezembro de 2018;

- Descritores de conteúdo utilizados: "decisões de processo”; "decisão de processo"; "decisões dos processos".
Para incluir na pesquisa as decisões de Autos de Infração, publicadas no período do estudo, foram considerados os seguintes critérios de inclusão:

- Nome fantasia;

- Cadastro Nacional da Pessoa Jurídica (CNPJ) do serviço/estabelecimento de alimentação, categorizado de acordo com a Instrução Normativa (IN) da Anvisa $\mathrm{n}^{\circ} 16$, de 26 de abril de $2017^{20}$ (anexa à RDC $n^{\circ} 153$, de 26 de abril de $2017^{21}$ ), a qual discorre quanto à "Lista de Classificação Nacional de Atividades Econômicas (CNAE) de atividades econômicas sujeitas à Vigilância Sanitária por grau de risco e dependente de informação para fins de licenciamento sanitário";

- Número e ano do processo administrativo;

- Número do Auto de Infração;

- Decisão e penalidade aplicada na decisão.

Como critérios de exclusão foram considerados os seguintes elementos:

- Estabelecimentos de serviço de alimentação com Cadastro de Pessoa Física (CPF);

- Hotéis, motéis, pousadas, escolas, hospitais e instituições para idosos, comércio atacadista de alimentos e outros estabelecimentos que não puderam ser identificados como serviço de alimentação;

- Estabelecimentos com CNPJ inválido;

- Dados omissos ou incorretos quanto ao número do Auto de Infração, número e ano do processo administrativo e penalidade aplicada.

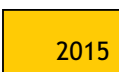

2015

2016

2017

2018
$24 / 08$

$24 / 03$

$29 / 09-07 / 11$

$06 / 02-13 / 10$

30/05-07/07

$28 / 02$

Fonte: Elaborada pelos autores, 2020.

Figura 1. Datas das publicações das decisões de processos administrativos em Diário Oficial do Município, por ano, segundo os descritores, no período 2015-2018. 
Todos os diários oficiais com os dados de interesse da pesquisa foram salvos e impressos. Em seguida, os documentos foram organizados cronologicamente para a leitura inicial que permitiu selecionar o corpus da pesquisa, usando os critérios de inclusão e exclusão. Para construção do banco de dados, foi feita a digitação e tabulação utilizando o software Microsoft Excel $®$, versão 2016, a partir de planilha elaborada pelos autores, contendo os seguintes campos: nome do estabelecimento, categoria, ano da lavratura do auto, penalidade aplicada e ano da publicação da penalidade no DOM. Para validar os dados quanto à categoria, foi utilizada a lista de estabelecimentos de baixo risco constante na IN n 16/201720. Para elaboração dos gráficos e tabelas de distribuição de frequências simples e relativas, os dados foram submetidos à análise de estatística descritiva.

\section{RESULTADOS}

Os resultados aqui apresentados correspondem ao período 20152018, destacando-se que somente em 2015 teve início a publicação no DOM das decisões de processos administrativos instaurados pela Visa Municipal. De acordo com a Figura 2, dos 509 processos do período estudado, destacam-se os anos 2016 e 2017, sendo que em 2016 o número de processos corresponde a $35,9 \%$ do total do período. 0 ano que apresentou o menor índice de autuações foi o de 2018 , com 65 casos que representa $12,8 \%$ do total.

No Quadro apresenta-se o número total de penalidades aplicadas, por tipo, em que já se destacam a advertência e a multa, sendo a advertência uma penalidade mais leve, e ambas aparecem tanto isoladamente, como cumulativamente com outras penalidades. Chama a atenção, contudo, o número de decisões por arquivamento.
Na Figura 3 verifica-se que, isoladamente, "advertência" ocorre em $31,4 \%$ das decisões proferidas, seguida por "multa" (20,2\%), e o "arquivamento" com 18,3\%. As penalidades de advertência e multa também aparecem cumuladas com outras penalidades, especialmente, com "inutilização de produtos", destacando-se a combinação desta com advertência, que teve 56 ocorrências $(11,0 \%)$, já a combinação de multa com inutilização de produto ocorreu 25 vezes (4,9\%). A ocorrência da "interdição total" do estabelecimento foi verificada em $10,0 \%$ dos casos, sempre cumulada com a inutilização de produtos, sendo que das 51 ocorrências, $43(8,4 \%)$ foram combinadas também com advertência e oito $(1,6 \%)$ com multa.

Quanto aos estabelecimentos autuados, a Tabela elenca o total por ramo de atividade, destacando-se "restaurantes e similares" (22,3\%), "supermercados e hipermercados" (10,3\%), seguidos de "lanchonetes, casas de chá, sucos e similares", "minimercados, mercearias e armazéns" (ambos com 6,9\%) e "padarias e confeitarias" $(6,0 \%)$. O maior percentual $(36,7 \%)$ é de estabelecimentos sem CNAE registrado no CNPJ, os quais foram incluídos no estudo porque, pelo nome fantasia, puderam ser reconhecidos como Serviços de Alimentação, conforme a RDC $n^{\circ} 216 / 2004^{10}$, e de baixo risco (conforme $I N^{\circ} 16 / 2017^{20}$ ), exceto no caso de padarias, pois somente pelo CNAE é possível distinguir a categoria de alto risco (CNAE 1091-1/01), excluída do estudo.

\section{DISCUSSÃO}

Neste estudo, é importante observar que a informação publicada no DOM, objeto da pesquisa, diz respeito às decisões de processos administrativos e não às infrações motivadoras do Auto de Infração, a partir do qual tem início o PAS. Como parte da

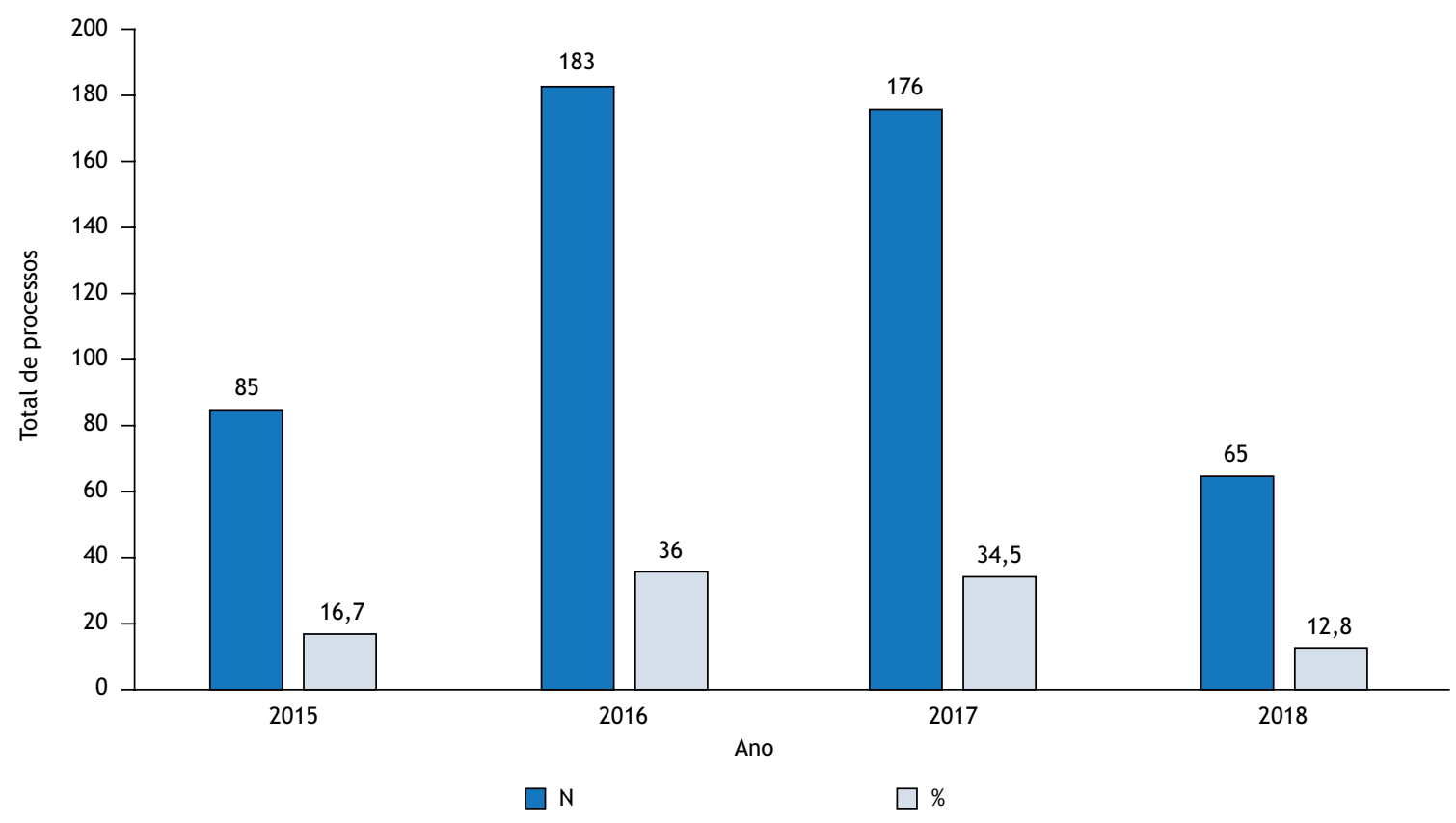

Fonte: Diário Oficial do Município, 2015 a 2018.

$\mathrm{N}$ : número de processos por ano; \%: percentual em relação ao total do período.

Figura 2. Distribuição dos processos administrativos abertos pela Vigilância Sanitária em serviços de alimentação com decisões publicadas no período 2015-2018. 
Administração Pública e por sua função regulatória, a vigilância sanitária tem forte interseção com o direito administrativo e está submetida aos princípios da Administração Pública, grafados

Quadro. Distribuição das decisões dos processos administrativos abertos pela Vigilância Sanitária em serviços de alimentação publicadas no período 2015-2018.

\begin{tabular}{|lc|}
\hline Decisões & N \\
\hline Advertência & 160 \\
Advertência + interdição de equipamento & 5 \\
$\begin{array}{l}\text { Advertência + interdição de equipamento + } \\
\text { inutilização de produto }\end{array}$ & 4 \\
Advertência + interdição parcial & 4 \\
Advertência + interdição parcial + inutilização de & 1 \\
produto & 39 \\
Advertência + interdição total & 4 \\
Advertência + interdição total + inutilização de & 56 \\
produto & 103 \\
Advertência + inutilização de produto & 1 \\
Multa & 43 \\
Multa + interdição de equipamento & 4 \\
Multa + interdição parcial & 7 \\
Multa + interdição total & 25 \\
Multa + inutilização de produto & 2 \\
Multa+ interdição de produto & 1 \\
Multa+ inutilização de produto + interdição total & 93 \\
Arquivamento & 4 \\
\hline
\end{tabular}

Fonte: Diário Oficial do Município, 2015 a 2018. no Art. 37 da Carta Magna vigente ${ }^{2}$. Deste modo, ressalta-se que a publicidade, um destes princípios, é fundamental para o controle da lisura dos atos da Visa e the garante legitimidade perante a população. Mesmo antes, o Art. 37 da Lei Federal $n^{\circ}$ 6.437, de 20 de agosto de $1977^{22}$, já estabelecia a obrigação de publicar nos meios oficiais a decisão final do PAS.

O direito à informação, assegurado pela Constituição Federal ${ }^{2}$, foi regulamentado pela LA ${ }^{19}$, que prevê duas formas de a Administração garantir acesso aos dados públicos: a forma passiva - quando atende demanda do cidadão que solicita os dados - e a forma ativa, quando a Administração divulga os dados de forma espontânea em canais de acesso público, independentemente de solicitação do cidadão. Neste caso, pode-se dizer que temos parcialmente a transparência ativa, uma vez que o cidadão tem a informação sobre decisões de processos administrativos instaurados pela Visa, mas não tem conhecimento das infrações cometidas. Alguns países como a Dinamarca ${ }^{23}$ e a Finlândia ${ }^{24}$, a partir de sistemas de informação específicos, têm adotado, como forma de aumentar a transparência pública e aprimorar o comprometimento dos estabelecimentos, a publicização na internet de seus relatórios de inspeção, o que tem contribuído para aumentar a percepção de risco do consumidor e influenciar suas escolhas de locais de consumo de alimentos ${ }^{23}$.

De todo modo, decisões publicadas significam processos concluídos, o que é um dado positivo importante, pois é fundamental a finalização do PAS com a devida publicidade da decisão, uma vez que a meta do Auto de Infração é o prosseguimento e finalização do processo ${ }^{17}$. Além disso, é mediante a publicidade da decisão

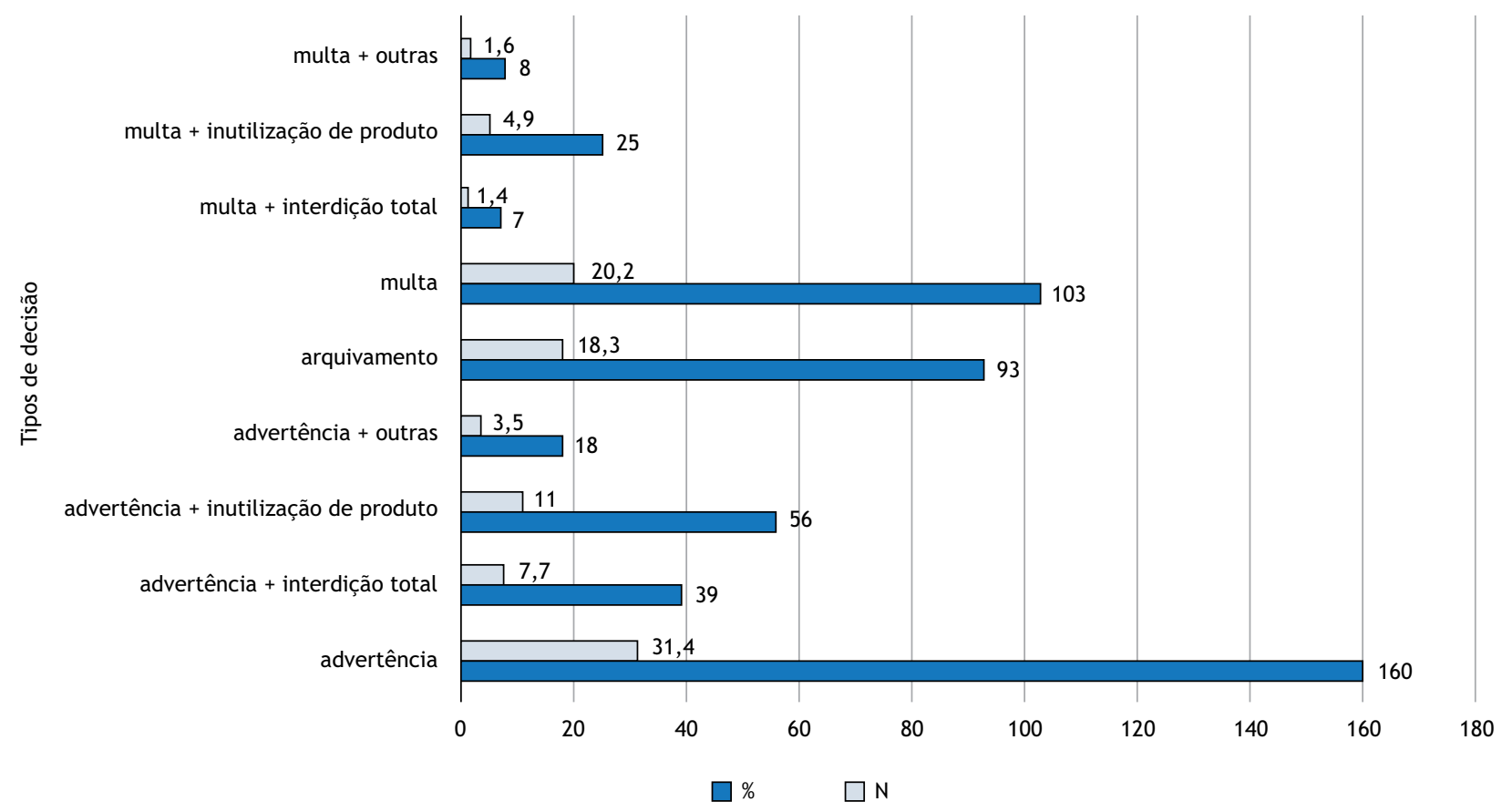

Fonte: Diário Oficial do Município, 2015 a 2018.

$\mathrm{N}$ : número de decisão aplicada; \%: percentual da decisão em relação ao total.

Figura 3. Distribuição das decisões dos processos administrativos abertos pela Vigilância Sanitária em serviços de alimentação publicadas no período 2015-2018. 
Tabela. Caracterização dos serviços de alimentação por ramo de atividade econômica com decisões de processos administrativos abertos pela Vigilância Sanitária publicadas no período de 2015 a 2018.

\begin{tabular}{|c|c|c|c|}
\hline Ramo de atividade & $\mathbf{N}$ & Fr (totEst) & Fr (com CNAE) \\
\hline Sem CNAE & 117 & $36,7 \%$ & - \\
\hline Restaurantes e similares & 71 & $22,3 \%$ & $35,1 \%$ \\
\hline Hipermercados e supermercados & 33 & $10,3 \%$ & $16,3 \%$ \\
\hline Lanchonetes, casas de chás, de sucos e similares & 22 & $6,9 \%$ & $10,9 \%$ \\
\hline Minimercados, mercearias e armazéns & 22 & $6,9 \%$ & $10,9 \%$ \\
\hline Padarias e confeitarias & 19 & $6,0 \%$ & $9,4 \%$ \\
\hline Bares e similares & 9 & $2,8 \%$ & $4,5 \%$ \\
\hline Serviços de alimentação para eventos e recepções, bufê & 7 & $2,2 \%$ & $3,5 \%$ \\
\hline Comércio varejista de carnes & 6 & $1,9 \%$ & $2,9 \%$ \\
\hline Comércio varejista de produtos alimentícios em geral & 7 & $2,2 \%$ & $3,5 \%$ \\
\hline Comércio varejista de doces, balas, bombons, similares & 3 & $0,9 \%$ & $1,5 \%$ \\
\hline Comércio varejista de mercadorias em lojas de conveniência & 3 & $0,9 \%$ & $1,5 \%$ \\
\hline Total & 319 & $100,0 \%$ & \\
\hline Total com CNAE & 202 & - & $100,0 \%$ \\
\hline
\end{tabular}

Fonte: Diário Oficial do Município, 2015 a 2018.

Fr(totEst): percentual em relação ao total de estabelecimentos; $\operatorname{Fr}($ comCNAE): percentual em relação aos estabelecimentos com CNAE.

que se poderá caracterizar a reincidência, tanto específica como inespecífica, pois, havendo decisão anterior, devidamente publicada, a reincidência poderá ser considerada uma circunstância agravante na próxima decisão ${ }^{22}$.

No período do estudo, conforme Figura 2, verifica-se uma concentração na publicação das decisões nos anos de 2016 e 2017. É importante ponderar que maior número de autuação não se traduz, necessariamente, em mudança de práticas no sentido de maior atenção aos aspectos higiênico-sanitários por parte dos estabelecimentos, embora isso possa ser esperado, em geral, pela população que acredita na força transformadora do poder de polícia. Se, por um lado, a presença de não conformidades detectadas no ato da inspeção, levando à autuação, pode ser considerada um indicador de baixa efetividade do controle sanitário, como propõe um estudo realizado na Suécia que analisou a frequência de não conformidades, os resultados mostraram, no caso de recorrentes autuações, ser mais comum nas inspeções subsequentes não perceber as não conformidades, ou seja, o risco de não conformidades não serem detectadas é maior onde muitas não conformidades já foram detectadas ${ }^{25}$. Deste modo, pode-se ter um círculo vicioso, em que mais autuações, ao longo do tempo, levariam a uma menor detecção de irregularidades, produzindo menor número de autuações, sem que isso decorresse de controle sanitário mais efetivo. Isso mostra a importância de a Visa utilizar outros instrumentos, como a educação e a comunicação do risco, junto à sociedade, e o treinamento e a supervisão dos agentes, como forma de promover um círculo virtuoso, do tipo mais educação, menos autuação, dito de outra maneira, mais prevenção, menos correção.

Ademais, considera-se curta a série histórica aqui obtida para se considerar alguma tendência, especialmente, porque não se contemplou o ano em que ocorreu a autuação, mas o ano no qual as decisões foram publicadas. Assim sendo, a partir dos dados obtidos neste estudo, em relação ao quantitativo de PAS, não é possível avaliar se há ou não excessos de autuação, seja pela falta de parâmetros, seja porque também não foi objeto do estudo o cadastro de estabelecimentos registrados no serviço de Visa, e só foram considerados Serviços de Alimentação de baixo risco. É certo que a ausência de um sistema municipal de informações em Visa é um fator que dificulta a construção de indicadores a partir dos dados obtidos ${ }^{26}$. No município estudado, a Visa não dispõe de um sistema de informação próprio, e os relatórios de inspeção ainda podem ser escritos à mão e sem a utilização de checklists, o que dificulta a sistematização dos dados coletados durante as visitas aos estabelecimentos. Por conseguinte, considera-se como limitação do estudo o fato da publicação oficial não citar o motivo da infração, prejudicando uma avaliação mais apurada dos fatores de risco e sua relação com a decisão.

Essa avaliação mostra a importância de a gestão desenvolver sistemas de informação e programas de capacitação de pessoal para utilização de critérios de risco no exercício do poder de polícia, apesar de se reconhecer que são inúmeras as dificuldades para cumprimento das normas, mesmo quando os serviços realizam inspeções e fazem trabalho de orientação ${ }^{24}$.

Em análise realizada na cidade de Cincinnati (Ohio, EUA), a partir de dados dos serviços de inspeção em alimentos, buscou-se relacionar infrações à norma sanitária com a classificação de risco, verificando-se que estabelecimentos de maior risco tinham mais chances de serem autuados ${ }^{27}$, embora essa classificação não seja a mesma utilizada no Brasil ${ }^{19}$.

Sabe-se que toda autuação decorre de uma infração à norma sanitária, e que o tipo de penalidade aplicada deve traduzir a gravidade da falta cometida, cabendo à autoridade sanitária, 
ao aplicar a penalidade, observar tanto a natureza e gravidade da infração e os prejuízos causados à Saúde Pública, como as circunstâncias atenuantes e agravantes e antecedentes do infrator ${ }^{22}$.

$\mathrm{Na}$ análise do perfil das penalidades aplicadas nos PAS instaurados pela Visa no período estudado (Figura 3), duas se destacam: advertências e multas, que respondem por mais de $80,00 \%$ do total, quando se considera sua aplicação isolada ou cumulativamente, sendo que a pena de "multa" e a pena de "advertência", aplicadas isoladamente constituem mais da metade $(51,70 \%)$ do total de penalidades.

A pena de advertência, em geral, é aplicada ao infrator primário (sem reincidência) e à infração de menor gravidade, sendo a multa um tipo de penalidade de maior grau ${ }^{22}$. A penalidade aplicada pela autoridade sanitária deve ser proporcional à gravidade do fato, em respeito ao princípio da proporcionalidade ${ }^{17}$, portanto, os resultados revelam que a Visa, no período estudado, optou pela pena de menor gravidade, que tem finalidade menos punitiva e mais educativa. Resultados semelhantes foram obtidos no sul do país, em que as medidas administrativas adotadas pela Visa, após a realização das inspeções, indicaram predomínio de medidas educativas $(65,64 \%)$ sobre as medidas punitivas (9,99\%), mesmo quando $70,00 \%$ dos estabelecimentos inspecionados apresentaram condições higiênico-sanitárias inadequadas $^{18}$. Por outro lado, o mesmo estudo reconhece a limitação das ações educativas como principal medida a ser adotada pelos agentes de inspeção, dada a complexidade do processo de trabalho em Visa, que envolve múltiplos atores, como o setor regulado e outros órgãos legisladores ${ }^{18}$.

Quanto à inutilização de produtos, trata-se de medida que tem a finalidade de proteger a população de um fator de risco à saúde, resultado de verificação in loco de produtos impróprios para o consumo, como também resultado de laudo condenatório emitido por laboratório oficial. Com essa medida repressiva ${ }^{3}$, que evita a exposição do consumidor a produtos que oferecem riscos à saúde, a Visa cumpre o seu papel de proteção da saúde. No caso dos alimentos contaminados, seu consumo poderia causar danos à saúde da população, caracterizando um grave problema de Saúde Pública ${ }^{28}$. A penalidade de "inutilização de produto" foi aplicada 91 vezes, sendo 65 cumulada com advertência e 26 com multa. A pena de "interdição total de estabelecimento" ocorreu em 51 casos, sendo 43 cumulados com "advertência" e oito com "multa".

Pode-se supor que, tanto a aplicação da interdição total de estabelecimento, como da inutilização de produtos foram resultados de situações de risco iminente à Saúde Pública ${ }^{17}$ detectadas pelo agente público no ato da inspeção, que expressam a autoexecutoriedade, característica do exercício do poder de polícia ${ }^{3}$, e sendo o administrado réu primário, optou-se pela advertência, ao invés da multa. Houve apenas dois registros de aplicação da pena de interdição de produto, ambos cumulados com multa. Cumpre esclarecer a diferença entre a interdição-pena e a interdição cautelar. A primeira é fruto de decisão final condenatória do processo; a segunda é objeto de ato processual preparatório, que exige laudo laboratorial definitivo ${ }^{29}$. Uma vez interditado, o estabelecimento pode voltar a funcionar tão logo apresente as condições necessárias indicadas pelo agente público, conforme a legislação vigente. No caso da interdição cautelar, porém, findo o prazo de 90 dias, caso o processo não seja concluído, o produto ou estabelecimento será automaticamente liberado.

Essa condição mostra o quão importante é o cumprimento dos prazos por parte da Administração ${ }^{29}$, que dispõe de cinco anos, contados da ocorrência da infração, para instaurar o PAS ${ }^{17}$, ou seja, há prazos prescricionais para o exercício punitivo e sancionatório do poder de polícia, de modo que se deve evitar infringir o princípio da oficialidade ${ }^{17,29}$. Arquivamentos podem ser indicativos da lentidão, inércia e/ou falha no trâmite processual. Como observa Ferreira ${ }^{30}$, em estudo que evidenciou fragilidades na instauração de PAS arquivados na Visa da Bahia, a falta de conclusão pode repercutir na permanência do risco para a Saúde Coletiva. Por isso, é preocupante a quantidade observada de decisões de arquivamento de processos $(18,30 \%)$, mas uma análise mais aprofundada acerca deste resultado está além dos propósitos deste estudo, já que não se teve acesso ao processo, apenas às decisões.

Por fim, a Tabela 1 mostra as categorias de Serviços de Alimentação que foram autuadas pela Visa, no período de quatro anos. As 509 decisões de processos foram aplicadas a 202 estabelecimentos que puderam ser categorizados em 11 ramos de atividade econômica, considerados de baixo risco de acordo com a IN $n^{\circ} 16 / 2017^{20}$. Nota-se, porém, que $36,7 \%$ das autuações correspondam a estabelecimentos que não puderam ser categorizados, por ausência de CNAE no registro no CNPJ, embora no nome fantasia indicasse ser um serviço de alimentação. Dentre as categorias encontradas, os estabelecimentos mais autuados foram "restaurantes e similares" (CNAE 5611-2/01) e "hipermercados e supermercados" (CNAE 4711-3/01), seguidos de "Lanchonetes, casas de chá, de sucos e similares” (CNAE 5611-2/03), "Minimercados, mercearias e armazéns" (CNAE 4712-1/00) e "Padaria e confeitaria", estes últimos incluem tanto "Fabricação de produtos de padaria e confeitaria com predominância de produção própria" (CNAE 1091-1/02), como "Padaria e confeitaria com predominância de revenda" (CNAE 4721-1/02), que são de baixo risco.

Tais resultados são compatíveis com estudo realizado a partir dos dados de inspeção sanitária realizada entre janeiro de 2005 e julho de 2015, em capital no sul do país, que revelou ser "minimercados, supermercados e hipermercados" o segmento que mais recebeu Autos de Infração e "restaurantes e similares", o que mais sofreu interdição ${ }^{18}$. Restaurantes e lanchonetes são também os locais com maior frequência de consumo de alimentos fora do lar, segundo estudo feito utilizando dados da Pesquisa de Orçamento Familiar (POF) 2008-2009 em uma amostra representativa da população brasileira ${ }^{7}$.

Estes dados merecem ser considerados na programação das ações da Visa, uma vez que tais categorias estão recebendo o alvará sanitário, sem inspeção prévia, desde 2017. A respeito disso, resultados de estudo realizado na Finlândia sugerem que a reintrodução da inspeção prévia à abertura dos estabelecimentos fortaleceria a adoção de boas práticas de manipulação de 
alimentos, pois os restaurantes não inspecionados previamente apresentaram significativamente mais não conformidades do que aqueles alvo de inspeções prévias ao início das atividades ${ }^{31}$.

É sabido que a produção e o consumo de alimentos em condições inadequadas estão entre os fatores que contribuem para a ocorrência de surtos de DTA, problema crescente no mundo, que tornou prioridade a inocuidade de alimentos e levou à criação de uma data mundial ${ }^{32,33}$. Além disso, considera-se imprescindível a implementação das boas práticas de manipulação de alimentos de forma mais intensificada, especialmente em um cenário de pandemia, como no caso do novo coronavírus (SARS-CoV-2), de forma a assegurar o fornecimento de alimento seguro, e proteger a saúde dos trabalhadores. Diante do exposto, fica evidente a relevância do cumprimento dos padrões higiênico-sanitários estabelecidos para a garantia da inocuidade do alimento, como componente da Política Nacional de Alimentação e Nutrição ${ }^{34}$ - que tem a regulação e o controle sanitário como uma de suas diretrizes - e da Segurança Alimentar e Nutricional, conforme estabelece o Art. $4^{\circ}$, IV da Lei 11.346 , de 15 de setembro de $2006^{35}$, na realização do direito humano à alimentação. Neste contexto, é fundamental consolidar a atuação regulatória da Visa baseada na gestão transparente da informação, de modo a garantir maior efetividade e legitimidade de suas intervenções perante a sociedade.

\section{CONCLUSÕES}

O estudo mostrou a importância da divulgação pelo serviço de Visa das decisões de seus processos administrativos sanitários e a necessidade de aprimoramento na garantia da transparência de seus atos. O Auto de Infração representa a necessária intervenção da Visa, quando falharam as medidas de prevenção e o controle dos fatores de riscos à saúde. Por este motivo, o conhecimento das infrações é importante para a gestão, mas a falta de um sistema de informações próprio do serviço de Visa, que apresente os estabelecimentos cadastrados e autuados, por distrito sanitário, bem como os relatórios de inspeção, dificulta a utilização desse importante instrumento para a construção de indicadores de avaliação. Por exemplo, seria importante para a gestão elaborar programas de intervenção em áreas onde fosse maior o número de autuações, ou voltados para as categorias de estabelecimentos mais autuadas, ou para sanar as irregularidades mais frequentes.

A sistematização e a avaliação de tais decisões podem ser ferramentas da própria gestão para elaborar a programação de ações visando um gerenciamento dos fatores de risco à saúde mais efetivo, como também um mecanismo de prestação de contas à sociedade. Por outro lado, os resultados apontam para a necessidade de maiores estudos que investiguem não apenas o aumento quantitativo das autuações por categoria de serviço de alimentação, como também as motivações dos Autos de Infração, de modo que os fatores de riscos à saúde possam ser melhor avaliados. Do ponto de vista do exercício do poder de polícia, caberia ainda acompanhar, em uma série histórica mais longa, a manutenção ou a alteração da proporção encontrada entre as penalidades de multa e de advertência.

\section{REFERÊNCIAS}

1. Brasil. Lei № 9.782, de 26 de janeiro de 1999. Define o Sistema Nacional de Vigilância Sanitária, cria a agência nacional de vigilância sanitária, e dá outras providências. Diário Oficial União. 27 jan 1999.

2. Senado Federal (BR). Constituição da República Federativa do Brasil. Brasília: Senado Federal; 1988.

3. Aith F, Minhoto LD, Costa EA. Poder de polícia e vigilância sanitária no estado democrático de direito. In: Costa EA, organizador. Vigilância sanitária: temas para debate. Salvador: Universidade Federal da Bahia; 2009. p. 37-60.

4. Brasil. Lei № 8.080, de 19 de setembro de 1990. Dispõe sobre as condições para a promoção, proteção e recuperação da saúde, a organização e o funcionamento dos serviços correspondentes e dá outras providências. Diário Oficial União. 20 set 1990.

5. Costa EA. Fundamentos da vigilância sanitária. In: Costa EA, organizador. Vigilância sanitária: temas para debate. Salvador: Universidade Federal da Bahia; 2009. p. 11-36.

6. Tancredi RCP, Fernandes ML. O poder público na aplicabilidade da norma. In: Marins BR, Tancredi RCP, Gemal AL, organizadores. Segurança alimentar no contexto da vigilância sanitária: reflexões e práticas. Rio de Janeiro: Escola Politécnica de Saúde Joaquim Venâncio; 2014. p. 69-91.

7. Bezerra IN, Moreira TMV, Cavalcante JB, Souza AM, Sichieri R. Consumo de alimentos fora do lar no Brasil segundo locais de aquisição. Rev Saude Publica. 2017;51:1-8. https://doi.org/10.1590/S1518-8787.2017051006750

8. Associação Brasileira das Empresas de Refeições Coletivas - Aberc. Mercado real. São Paulo: Associação Brasileira das Empresas de Refeições Coletivas; 2008[acesso 3 mar 2021]. Disponível em: https://aberc. com.br/mercadoreal.asp?IDMenu=21

9. Ministério da Saúde (BR). Surtos de doenças transmitidas por alimentos no Brasil. Brasília: Ministério da Saúde; 2019[acesso 3 mar 2021]. Disponível em: https://portalarquivos2.saude.gov.br/ images/pdf/2019/fevereiro/15/Apresenta----o-Surtos-DTA--Fevereiro-2019.pdf

10. Agência Nacional de Vigilância Sanitária - Anvisa. Resolução RDC № 216, de 15 de setembro de 2004. Dispõe sobre o regulamento técnico de boas práticas para serviços de alimentação. Diário Oficial União. 16 set 2004. 
11. Cardoso RCV, Góes JAW, Almeida RCC, Guimarães AG, Barreto DL, Silva SA et al. Programa nacional de alimentação escolar: há segurança na produção de alimentos em escolas em Salvador (Bahia)? Rev Nutr. 2010;23(5):801-11. https://doi.org/10.1590/S1415-52732010000500010

12. Santos MOB, Rangel VP, Azeredo DP. Adequação de restaurantes comerciais às boas práticas. Rev Hig Alim. 2010;24(190/1):44-9.

13. Souza CVS, Calazans DLMS, Bagni UV. Gestão de equipamentos públicos de segurança alimentar $\mathrm{e}$ nutricional: uma abordagem sobre a dimensão da qualidade da refeição servida no restaurante popular. In: Araújo MAD, Araujo RM, organizadores. Políticas públicas: segurança alimentar e nutricional e desenvolvimento rural no Rio Grande do Norte. Natal: Universidade Federal do Rio Grande do Norte; 2016. p. 247-87.

14. Ribeiro VF, Matté GR. Análise da produção acadêmica em vigilância sanitária de alimentos, 1993-2007. Rev Saude Publica. 2010;44(6):1155-8. https://doi.org/10.1590/S0034-89102010000600023

15. Steinbach A, Schwengber LMK, Martins C, Dutra A, Venâncio $D$, Silva $M Z$. Mapeamento da produção científica em gestão da vigilância sanitária no período 2000 a 2010. Rev Gest Saude. 2012;3(3):919-40.

16. Agência Nacional de Vigilância Sanitária - Anvisa. Agenda nacional de prioridades de pesquisa em vigilância sanitária. Brasília: Agência Nacional de Vigilância Sanitária; 2011.

17. Lima YOR, Costa EA. O processo administrativo no âmbito da vigilância sanitária. In: Costa EA, organizador. Vigilância sanitária: temas para debate. Salvador: Universidade Federal da Bahia; 2009. p. 195-218.

18. Olmedo PV, Stangarlin-Fiori L, Medeiros CO, Tondo EC, Ferreira SMR. A profile of foodservices in Curitiba and a critical analysis of the results of sanitary inspections at these establishments. J Food Saf. 2018;38(1). https://doi.org/10.1111/jfs. 12377

19. Brasil. Lei $N^{\circ} 12.527$, de 18 de novembro de 2011. Regula o acesso a informações previsto no inciso 33 do artigo 5 , no inciso 2 do parágrafo 3 do artigo 37 e no parágrafo 2 do artigo 216 da constituição federal; altera a lei $N^{\circ} 8.112$, de 11 de dezembro de 1990; revoga a lei $\mathrm{N}^{\circ} 11.111$, de 5 de maio de 2005, e dispositivos da lei $\mathrm{N}^{\circ} 8.159$, de 8 de janeiro de 1991; e dá outras providências. Diário Oficial União. 19 nov 2011.

20. Agência Nacional de Vigilância Sanitária - Anvisa. Instrução normativa № 16, de 26 de abril de 2017. Dispõe sobre a lista de classificação nacional de atividades econômicas, CNAE, classificadas por grau de risco para fins de licenciamento sanitário. Diário Oficial União. 27 abr 2017.

21. Agência Nacional de Vigilância Sanitária - Anvisa. Resolução RDC No 153, de 26 de abril de 2017. Dispõe sobre a classificação do grau de risco para as atividades econômicas sujeitas à vigilância sanitária, para fins de licenciamento, e dá outras providências. Diário Oficial União. 27 abr 2017.
22. Brasil. Lei $\mathrm{N}^{\circ} 6.437$, de 20 de agosto de 1977. Configura infrações à legislação sanitária federal, estabelece as sanções respectivas, e dá outras providências. Diário Oficial União. 24 ago 1977.

23. Vainio A, Kaskela J, Finell E, Ollila S, Lundén J. Consumer perceptions raised by the food safety inspection report: does the smiley communicate a food safety risk? Food Control. 2020;110:1-8. https://doi.org/10.1016/j.foodcont.2019.106976

24. Kettunen K. Food safety enforcement at the local level in Finland: risk-basis, efficacy and consistency [dissertação]. Helsinki: Univesity of Helsinki; 2018.

25. Berking $\mathrm{C}$, Vågsholm I, Hedberg LM, Sörgjerd $\mathrm{S}$, Niskanen R. Non-compliances: an indicator of food control effectiveness. Infec Eco Epidem. 2019;9(1):1-10. https://doi.org/10.1080/20008686.2019.1599276

26. Felisberto E, Brito RL, Barca DAAV, Martins MAF, Oliveira AKNBM, Souza NC et al. Modelagem avaliativa para a construção de indicadores de efetividade das ações de vigilância sanitária no Brasil. Rev Bras Saude Mater Infant. 2018;18(3):665-76. https://doi.org/10.1590/1806-93042018000300011

27. Chang P, Rochani H, Mase WA, Jones JA, Aslan A. Analysis of food service operation risk classification and associated food safety violation frequency. J Envir Health. 2018;80(6):14-8.

28. Oliveira ABA, Paula CMD, Capalonga R, Cardoso MRI, Tondo EC. Doenças transmitidas por alimentos, principais agentes etiológicos e aspectos gerais: uma revisão. Rev HCPA. 2010;30(3):279-85.

29. Agência Nacional de Vigilância Sanitária - Anvisa. Manual de processo administrativo sanitário. Brasília: Agência Nacional de Vigilância Sanitária; 2014[acesso 3 mar 2021]. Disponível em: https://xdocs.com.br/doc/ manual-pasal-livro2-pratica-48gpw7m02782

30. Ferreira LC. O processo administrativo sanitário e o direito à saúde. Rev Baiana Saúde Pública. 2015;38(4):803-20. https://doi.org/10.22278/2318-2660.2014.v38.n4.a732

31. Haukijärvi V, Lundén J. Does waiving preventive food control inspections in Finland weaken the prerequisites for safe food handling in restaurants? Food Control. 2017;71:187-92. https://doi.org/10.1016/j.foodcont.2016.06.044

32. World Health Organization - WHO. World food safety day 2020: food safety, everyone's business. Brussels: World Health Organization; 2020[acesso 3 mar 2021]. Disponível em: https://www.who.int/news-room/ initiatives/world-food-safety-day-2020

33. Silveira JT, Brasil CCB, Floriano JM, Garcia MV. Higiene dos serviços de alimentação no Brasil: uma revisão sistemática. Saude Rev. 2016;16(42):57-69. https://doi.org/10.15600/2238-1244/sr.v16n42p57-69

34. Ministério da Saúde (BR). Portaria № 2.715, de 17 de novembro de 2011. Atualiza a política nacional de alimentação e nutrição. Diário Oficial União. 18 nov 2011. 
35. Brasil. Lei № 11.346, de 15 de setembro de 2006. Cria o sistema nacional de segurança alimentar e nutricional Sisan com vistas em assegurar o direito humano à alimentação adequada e dá outras providências. Diário Oficial União. 18 set 2006.

\section{Contribuição dos Autores}

Soares S, Seabra LMJ, Rolim PM - Concepção e planejamento (desenho do estudo), aquisição, análise, interpretação dos dados e redação do trabalho. Pessoa RL - Aquisição, análise, interpretação dos dados e redação do trabalho. Lima REP - Análise, interpretação dos dados e redação do trabalho. Todos os autores aprovaram a versão final do trabalho.

Conflito de Interesse

Os autores informam não haver qualquer potencial conflito de interesse com pares e instituições, políticos ou financeiros deste estudo.

Licença CC BY-NC atribuição não comercial. Com essa licença é permitido acessar, baixar (download), copiar, imprimir, compartilhar, reutilizar e distribuir os artigos, desde que para uso não comercial e com a citação da fonte, conferindo os devidos créditos de autoria e menção à Visa em Debate. Nesses casos, nenhuma permissão é necessária por parte dos autores ou dos editores. 